Zendri, L. La protección del patrimonio cultural de Argentina. De la legislación patrimonial a la consagración de un nuevo derecho. Derecho y Ciencias Sociales. Abril 2017. № 16 (Temas relativos al desarrollo regional y local) Pgs 40- 55. ISNN 1852-2971. Instituto de Cultura Jurídica y Maestría en Sociología Jurídica. FCJ y S. UNLP.

\title{
La protección del patrimonio cultural de Argentina.
}

\section{De la legislación patrimonial a la consagración de un nuevo derecho.}

\author{
The protection of the cultural heritage of Argentina. \\ From the patrimonial legislation to the consecration of a new law.
}

\section{Liliana Zendri ${ }^{\bullet}$}

\section{Resumen.}

Esta cuestión puede encararse de distintas aristas, trabajamos un concepto multívoco que incluye múltiples categorías (patrimonio urbano, urbanístico, edificado, artístico, histórico, etc.) y es pilar de desarrollo local y regional. Su régimen jurídico es relevante porque su dimensión desborda la tutela municipal y la legislación especial (donde cada ley atiende determinado objeto). Cuando debe analizarse de manera integral sea en el ordenamiento interno, en normas internacionales (cartas e instrumentos emanadas de organismos internacionales especializados) como la recepción en constituciones europeas y latinoamericanas, para atender adecuadamente la incorporación por nuestra Constitución Nacional (y cartas provinciales), en armonía con principios generales y normas rectoras globales. En la tutela jurídica resalta la importancia del tránsito operado desde las variadas leyes especiales (legislación patrimonial) a la incorporación con rango constitucional del "Derecho al patrimonio cultural y a la identidad cultural", ya que la reforma positivizó el derecho con rango constitucional ordenando dictar una ley de presupuestos mínimos. Es importante dictar una Ley General de Patrimonio Cultural pero hacerlo en sintonía al nuevo derecho, que ponga eje en las misiones y funciones de las instituciones de preservación, conservación, difusión, y especialmente de tutela jurídica, atendiendo obligaciones del Estado, del colectivo social y la responsabilidad de las instituciones de enseñanza, para generar espacios académicos, cooperación y estudios (locales, regionales e internacionales).

Palabras clave: protección, patrimonio cultural, legislación, nuevo derecho.

\begin{abstract}
.
This issue can be approached from different angles, we work on a multivocal concept that includes multiple categories (urban patrimony, built, artistic, historic, etc.) and it is a pillar of local and regional development. Its legal regime is relevant because its dimension exceeds municipal protection and special legislation (where each law serves a particular purpose). When international norms (letters and instruments emanating from specialized international organizations) and reception in European and Latin American constitutions must be analyzed in an integral way, in order to adequately address the incorporation by our National Constitution (and provincial letters), in harmony with general principles and global guiding norms. In the legal guardianship, the importance of the transit from the various special laws (patrimonial legislation) to the incorporation with the constitutional rank of "Right to the cultural heritage and the cultural identity", since the reform positivized the right with constitutional rank ordering to dictate a law of minimum budgets. It is important to enact a General Law on Cultural Heritage, but to do so in harmony with the new law, which is central to the missions and functions of institutions for preservation, conservation, diffusion and especially legal protection, attend to obligations of the State, the responsibility of educational institutions, to generate academic spaces, cooperation and studies (local, regional and international).
\end{abstract}

Key words: Protection, cultural heritage, legislation, new law.

\footnotetext{
- Liliana Zendri, abogada, especialista en Derecho Civil (UNLP), magíster en Conservación del Patrimonio Cultural (UNIA-CE); investigadora categorizado UNLP; docente de grado y posgrado FCJS y en Especialización en patrimonio arquitectónico y urbano de FAU; profesora de maestría en Derecho Procesal Constitucional (IEA/UNLZ). Fue coordinadora de Sede Permanente de Forum UNESCO: Universidad y Patrimonio en FCJS, miembro de Asociación Argentina de Estudios Canadienses área "Patrimonio Cultural" y responsable-directora de Cátedra Libre: "Patrimonio e Identidad Cultural" de UNLP. Actualmente es miembro del Instituto de Cultura Jurídica de UNLP y de la Asociación Argentina de Derecho Procesal Constitucional (AADPC). e-mail: lilianazendri@hotmail.com; lzendri@jursoc.unlp.edu.ar
} 
Zendri, L. La protección del patrimonio cultural de Argentina. De la legislación patrimonial a la consagración de un nuevo derecho. Derecho y Ciencias Sociales. Abril 2017. № 16 (Temas relativos al desarrollo regional y local) Pgs 40- 55. ISNN 1852-2971. Instituto de Cultura Jurídica y Maestría en Sociología Jurídica. FCJ y S. UNLP.

\section{La protección del patrimonio cultural de Argentina.}

De la legislación patrimonial a la consagración de un nuevo derecho.

Liliana Zendri

\section{Introducción.}

Son variadas las aristas para abordar la cuestión del patrimonio cultural (PC) el que además, presenta múltiples categorías (patrimonio construido, edificado, etc.), y visto que es un elementos que -enfocado adecuadamente- pueden ser uno de los pilares del desarrollo local y regional, debemos aclarar de inicio que estas reflexiones, enfocan de su régimen jurídico, sólo un aspecto, cual es el transito operado en Argentina desde la concepción que entendía su tutela mediante leyes especiales (la llamada "Legislación Patrimonial") a la incorporación constitucional (con la reforma de 1994) del denominado "Derecho al patrimonio cultural (DPC)", dando cuenta de la observación efectuada en marco de un proyecto de investigación de la UNLP denominado "Crisis internacional y sus efectos sobre el desarrollo regional y local".

Estamos asimismo obligados, a señalar la relación que existe con la identidad cultural ${ }^{1}$ como también la necesidad de atender las funciones de los encargados de su tutela, ya que la citada reforma incorporó a la Constitución Nacional la "tercera" generación de derechos, positivizando el "Derecho al patrimonio y a la identidad cultural" -entre otros de su clase-, pero además, estableciendo la manda de dictar una ley de presupuestos mínimos que (a más de veinte años), continúa siendo un mandato incumplido.

Esto último, ha hecho que desde hace tiempo hablemos de la oportunidad de dictar una Ley General de Patrimonio y aunque este trabajo no pone eje en ello, es imprescindible señalar la necesidad de una ley marco, dictada en sintonía al "nuevo derecho" y a la oportunidad de observar otras experiencias del derecho comparado sobre instituciones de preservación, tutela y difusión, donde ubica -asimismo- la misión de quienes tienen obligación de "formar" en estos temas generando espacios académicos, desarrollando cooperación para participar de grupos de trabajo y estudios (locales, regionales e internacionales), lo que tiene enorme relevancia a nivel mundial.

\section{Dimensión de la cuestión patrimonial.}

\footnotetext{
${ }^{1}$ Conf. su consagración conjunta en nuestra norma fundamental
} 
Zendri, L. La protección del patrimonio cultural de Argentina. De la legislación patrimonial a la consagración de un nuevo derecho. Derecho y Ciencias Sociales. Abril 2017. № 16 (Temas relativos al desarrollo regional y local) Pgs 40- 55. ISNN 1852-2971. Instituto de Cultura Jurídica y Maestría en Sociología Jurídica. FCJ y S. UNLP.

Un punto insoslayable, es el correcto abordaje porque frecuentemente la cuestión se atiende en derecho interno, desde una mirada local (legislaciones municipales o políticas y/o programas preservacionistas) y -en general- de la óptica del Estado, o sea, no se analiza su dimensión real que desborda la tutela municipal y aún la "legislación patrimonial" (leyes especiales cada una de las cuales atiende un determinado objeto del patrimonio, recortando considerar otros aspectos). Así, debe relacionarse el orden interno, las normas internacionales (cartas e instrumentos internacionales emanadas de organismos especializados) y la forma de recepción en las constituciones europeas y latinoamericanas, aspectos a considerar en la protección patrimonial en cada Estado, por tanto en el nuestro, al analizar la incorporación en la C.N. (para hacerlo en armonía con los principios generales emanados de las normas rectoras a nivel global).

Argentina consagró en la Constitución Nacional (y en muchas cartas provinciales), el DPC, dándole carácter de derecho colectivo y ubicándolo de manera que su fuente torna relevante, pues esta categoría de derechos ha dado lugar a una rama de la ciencia jurídica de importante desarrollo en derecho comparado ${ }^{2}$ conocida como constitucionalismo cultural, aunque también, anida en el ambientalismo, al comprender nociones que se confunden en cuanto al modo de hacer efectiva la protección legal, razón por la cual se debe bucear en dichas fuentes buscando la filosofía de la recepción constitucional, por las implicancias que eso trae, atento de ahí, derivan las obligaciones de tutela del Estado (autoridades), de los particulares y para la sociedad.

Como se dijo. nuestro país requiere normas que completen y/o complementen la incorporación constitucional de este "nuevo derecho", no sólo porque el convencional constituyente así lo dejo establecido, sino también porque la recepción del DPC vino a impactar en un ordenamiento preexistente, que debe en consecuencia, al tiempo de interpretarse sus normas, analizarse en su integralidad a fin de evitar contradicciones, redundancias y aún lagunas o inconsistencias de cualquier tipo, que lleven a la ausencia de sistematización y armonía normativa imprescindible, ya que su ausencia conduce inexorablemente -en la materia- a un régimen jurídico que no cumple su función esencial: la de proteger los bienes que conforman nuestro PC .

El mismo texto constitucional -conf. nuestro federalismo- establece que corresponde a la Nación dictar normas que contengan presupuestos mínimos de protección y a las Provincias lo

\footnotetext{
${ }^{2}$ Impulsada -en gran medida- por la actividad de organismos intergubernamentales.
} 
Zendri, L. La protección del patrimonio cultural de Argentina. De la legislación patrimonial a la consagración de un nuevo derecho. Derecho y Ciencias Sociales. Abril 2017. № 16 (Temas relativos al desarrollo regional y local) Pgs 40- 55. ISNN 1852-2971. Instituto de Cultura Jurídica y Maestría en Sociología Jurídica. FCJ y S. UNLP.

necesario para complementarlas; es decir, la $\mathrm{CN}$ manda dictar una ley (art. 41) y vincula al art. 75 inc. 22 al decir que corresponde al Congreso -entre otras obligaciones-, la de "dictar leyes que protejan la identidad y pluralidad cultural, la libre creación y circulación de las obras del autor, el patrimonio artístico y los espacios culturales...”, y al inc. 23: “...legislar y promover medidas de acción positiva que garanticen... el pleno goce y ejercicio de los derechos reconocidos por ésta Constitución y por los tratados internacionales...".

La consecuencia de ello es la necesidad de poner en agenda el rol de las instituciones (todas), en primer lugar, la del legislador nacional y provincial (conforme sus respectivas competencias), aunque también la de las instituciones, especialmente la de aquellas destinadas a gestionar el PC, porque se requiere analizar cómo queda delineada -después de la reforma- la obligación del Estado (autoridades) y del colectivo social todo en su tutela, donde cabe atender la responsabilidad de las instituciones de enseñanza en la cuestión.

El tema es de complejidad, o al menos, tiene numerosos y variados aspectos a tener en cuenta, frente a la pretensión de dar tutela efectiva de nuestro PC.

Por eso nos parecen oportunas algunas precisiones preliminares que son núcleo de coincidencia doctrinaria, sin perjuicio de otras propias del ámbito (lugar) bajo análisis.

1) Poner en relieve que los bienes culturales (BC) tienen naturaleza propia pues "patrimonio cultural" es una noción amplia que alude a bienes materiales e inmateriales (intangibles) asociados a la tradición cultural de una comunidad o un sitio y por tanto incluye: a) bienes inmuebles: edificios y viviendas de especial interés, agrupamientos urbanos destacados por su valor (artístico, arqueológico, paisajístico, etc.); b) bienes muebles: obras de arte, libros, documentos, archivos etc.; y c) bienes intangibles: tradición oral, música, artes escénicas, ritos, costumbres, sistema de valores y derechos.

2) Señalar que más allá de que existan leyes especiales dedicadas cada una a bienes (o categoría de ellos), se debe delimitar conceptualmente el universo de los "elementos" que conforman el PC en cada ciudad, país o nación, como inicial decisión para encarar una política patrimonial integral, incluida la legislativa.

3) La noción, involucra bienes públicos y privados haciendo que la clasificación (bienes del dominio público/bienes del dominio privado) ceda frente al "Derecho al uso y disfrute de los bienes del PC", porque ellos son una categoría especial, que la doctrina denomina de manera diversa, pero son siempre de "disfrute compartido" (Orozco Pardo y Perez Alonso, 1996 y Zannoni).

En nuestro ámbito, a esas cuestiones básicas, suman otras que son propias, así: 
Zendri, L. La protección del patrimonio cultural de Argentina. De la legislación patrimonial a la consagración de un nuevo derecho. Derecho y Ciencias Sociales. Abril 2017. № 16 (Temas relativos al desarrollo regional y local) Pgs 40- 55. ISNN 1852-2971. Instituto de Cultura Jurídica y Maestría en Sociología Jurídica. FCJ y S. UNLP.

a. Los aspectos dominiales. Debe tenerse presente que el Código Civil argentino consagra el derecho de propiedad privada con caracteres de exclusivo, absoluto y perpetuo con la sola limitación al ejercicio regular del derecho y la restricción de ser susceptibles (ciertos bienes) de expropiación por causa de utilidad pública. En esta materia, sin embargo, el avance del constitucionalismo ambiental-cultural (donde ubica la cuestión) considera que los bienes culturales tienen una "fruición colectiva" separable de la cosa sobre la que asienta; de manera tal que frente a los bienes del PC se pretende que independiente de la titularidad dominial del bien ${ }^{3}$, se genere el convencimiento de que la política preservacionista debe estar respaldada por la necesidad de restringir (a veces) al titular de determinados bienes, para cumplir con el fin administrativo de su conservación, con el uso y goce aludido de los bienes del PC, con los intereses públicos y con el deber mismo de preservar valores culturales y arquitectónicos de bienes (en particular edificios), por lo que ellos representan a su comunidad.

b. La extensión de la noción "bien cultural". Frente a la elaboración de una ley marco sobre protección de los $\mathrm{BC}$, cabe tener presente que la noción conceptual superó la referencia original al monumento y obra de arte como objeto de tutela, para llegar a abarcar una pluralidad y diversidad de elementos, alcanzando derechos fundamentales, el sistema de valores y las tradiciones de la comunidad, ya que numerosos aspectos caracterizan a cada pueblo, de ahí , la necesidad de poner en valor los bienes identitarios y la de crear un marco jurídico óptimo, que articule (en nuestro caso) con la protección de la identidad cultural (conforme quedó redactado en $\mathrm{CN}$ ), para su efectiva tutela.

c) La consagración del DPC en Argentina. Debe recordarse que además del constitucionalismo cultural, la cuestión apoya asimismo en lo ambiental, porque su recepción, se produce en la norma que consagra el Derecho al ambiente (art. 41 de $\mathrm{CN}$ ), que incorpora conjuntamente la preservación de la naturaleza, la explotación racional de recursos naturales y culturales, la preservación del patrimonio y la identidad cultural ${ }^{4}$.

En síntesis, la reforma nacional en Argentina, cambió sustancialmente la cuestión y obliga a considerar que: Antes de la reforma, el PC se estudiaba mediante la llamada "legislación del patrimonio" con reenvío a numerosas leyes, pues existe un universo de bienes que

\footnotetext{
${ }^{3}$ Puede ser del Estado, particulares e incluso de la Iglesia.

${ }^{4}$ Nos parece mejor la técnica usada por el convencional provincial en la CPBA que en el art.28 consagra y tutela el ambiente (y por esa vía los elementos que componen el hábitat humano), pero agregó el art. 44, norma específica "de protección de acervo cultural" que alude expresamente a las manifestaciones: cultural, histórico, arquitectónico, arqueológico y urbanístico, citando todo aquello que afirme la identidad y poniendo en cabeza del Estado provincial la obligación de preservarlo, enriquecerlo y difundirlo, como también la de proteger sus instituciones.
} 
Zendri, L. La protección del patrimonio cultural de Argentina. De la legislación patrimonial a la consagración de un nuevo derecho. Derecho y Ciencias Sociales. Abril 2017. № 16 (Temas relativos al desarrollo regional y local) Pgs 40- 55. ISNN 1852-2971. Instituto de Cultura Jurídica y Maestría en Sociología Jurídica. FCJ y S. UNLP.

conforman el concepto "patrimonio" y por tanto existe una frondosa legislación especial ${ }^{5}$, normas generales (nacionales o provinciales) sin perjuicio de la articulación con normas municipales (locales); la reforma constitucional (94) al incorporar el "DPC" con remisión al "ambiente" y en el capítulo "nuevos derechos", le da además de lo expresado, dimensión de derecho humano, fijando la responsabilidad inter generacional de tutela.

Como vemos, es necesario además, determinar qué bienes integran el PC en su localización, porque cada pueblo tiene bienes que lo identifican; por tanto, trabajamos con una noción amplia y variable de ahí que existan diversos regímenes jurídicos (diferenciados de un lugar a otro) donde además de la variabilidad de cada tipo de objeto ${ }^{6}$, cabe analizarse la titularidad.

En Argentina los bienes que integran el PC de la nación son enumerados en Ley $25.197^{7}$ que crea el Registro Único de Bienes Culturales, que aunque muy criticada tiene el mérito de su art. 2, que contiene un extenso listado (catálogo) de los mismos.

Se dijo antes que aún superada la cuestión conceptual o al menos delimitada en nuestro país conforme la antedicha ley, aparece la relación existente entre patrimonio (especialmente lo atinente a bienes del patrimonio arquitectónico y urbanístico) y derecho de propiedad, ya que éste es un capítulo relevante no sólo a la cuestión constitucional sino además, en lo relativo a la gobernanza y al sistema de derechos todo.

Lo dicho, nos deja enumeradas cuestiones que requieren especial desarrollo pero que solo las enunciamos, para señalar la importancia de la "real dimensión" de los aspectos previos, contenidos en la tutela jurídica del PC.

\section{Inclusión del patrimonio cultural en la norma constitucional de Argentina.}

\subsection{Norma ambiental.}

Queda claro, que la recepción del DPC en nuestra nación se produjo en la "norma ambiental"8 (art. $41 \mathrm{CN}$ ) en capítulo "nuevos derechos", regla que comprende también las correlativas obligaciones del Estado y la sociedad (al decir "todos los habitantes...").

\footnotetext{
${ }^{5}$ L. 9.080 (1912) que declara de propiedad de la Nación: ruinas y yacimientos arqueológicos y paleontológicos de interés científicos; L. 12.655 (1940) que crea la Comisión Nacional de Museos, Monumentos Lugares y Sitios Históricos; L. 24.663 de circulación internacional de obras de arte; L.25.197 Régimen del Registro del Patrimonio Cultural de la Nación; L. 25.743 (2003) de Protección del patrimonio arqueológico y paleontológico; además, numerosas leyes provinciales, decretos reglamentarios etc., sin perjuicio del poder de policía local, entre otras.

${ }^{6}$ Cada "elemento" del PC plantea requerimientos propios de tutela por eso para su adecuado tratamiento será necesario -en primer lugar- haber determinado a qué categoría de bien corresponde. Se requiere establecer qué objetos son un "bien cultural" en su localización, atender las "operaciones de intervención" efectuadas y/o requeridas sobre el bien de que trate y ubicarlo en el régimen jurídico que corresponda, ya que no va a ser igual por ejemplo, la tutela y conservación de un centro histórico que la de otros bienes o elementos que conforman el patrimonio cultural.

${ }^{7}$ Ley 25.197, B.O. del 15/12/1999 (ADLA 1999-D, 4283).
} 
Zendri, L. La protección del patrimonio cultural de Argentina. De la legislación patrimonial a la consagración de un nuevo derecho. Derecho y Ciencias Sociales. Abril 2017. № 16 (Temas relativos al desarrollo regional y local) Pgs 40- 55. ISNN 1852-2971. Instituto de Cultura Jurídica y Maestría en Sociología Jurídica. FCJ y S. UNLP.

Del "ambiente", es sabido es que el ser humano tiene derecho a disfrutar de todas las condiciones del mismo. por eso no basta sea sano, sino que además debe reunir otros presupuestos; nuestra carta dice “...derecho a un ambiente sano, equilibrado, apto para el desarrollo humano...", estableciendo que corresponde al legislador al reglamentar el derecho, determinar qué cosas abarca el concepto.

Es que para el constituyente, "ambiente" en dimensión amplia, incluye la obligación de proteger los recursos naturales renovables y no renovables, la de preservar el patrimonio en sus diversas manifestaciones, vinculando a la identidad cultural $^{9}$, lo que llevó a la incorporación expresa de estos derechos de manera conjunta en la $\mathrm{CN}$, poniendo en resalto la importancia de ir creando un marco institucional más propicio y conveniente al cambio de paradigma que significaba. El citado art. 41, incorpora derechos dando soporte constitucional a los reclamos sobre medio ambiente en general... la explotación racional de recursos... el patrimonio y la identidad de los pueblos, entre otros, pero también establece que corresponde a la nación dictar normas de presupuestos mínimos de protección y a las provincias las necesarias para complementarlas.

Esto último equivale -.como se dijo- a que se debe dictar una ley marco, que en lo estrictamente ambiental vincula a la Ley $25.675^{10}$, pero respecto los bienes del PC en sentido estricto, sin analizar el contenido que corresponda a esta ley, es de señalar que conforme quedó la cuestión con la positivización del derecho, en nuestro ordenamiento hay hoy falta de sistematización en la cuestión patrimonial y por otro lado, y atento las normas deben ser interpretadas armónicamente, debe atenderse el art. 75, citado ut supra, que se dijo, fija que corresponde al Congreso: inc. 19) "Proveer lo conducente al desarrollo humano...".

Muestra entonces que el "ambiente" acopla al "desarrollo" porque nuestra constitución consagra la obligación de que éste último, no descuide la protección del primero en sus aspectos natural y cultural, haciendo que la actividad de esta cuestión deba orientarse en perspectiva generacional, y aunque sepamos, que esto no haya alcanzado para detener la sobreexplotación de nuestros recursos. De ahí que se insista en buscar soluciones propias pero en la conveniencia de implementar políticas de desarrollo compatibles con la preservación de

\footnotetext{
${ }^{8}$ Háberle P., en "La Protección constitucional y universal de los bienes culturales..." dice "...es especialmente llamativo el contexto en que por regla general, casi siempre se encuentra la protección constitucional de la cultura y de la naturaleza... llamativo es el rango otorgado a la protección de los bienes culturales (nacionales) y la alusión a la cultura y la naturaleza en el mismo texto...”.

${ }^{9}$ La memoria de un sitio (pueblo o ciudad) está amalgamada a los bienes en que expresa, por esta razón, preservar estos bienes identitarios es una forma de tutelar sus raíces.

${ }^{10}$ Ley General del Ambiente. Sanción: 2002/11/06 . B.O. 202/11/28.
} 
Zendri, L. La protección del patrimonio cultural de Argentina. De la legislación patrimonial a la consagración de un nuevo derecho. Derecho y Ciencias Sociales. Abril 2017. № 16 (Temas relativos al desarrollo regional y local) Pgs 40- 55. ISNN 1852-2971. Instituto de Cultura Jurídica y Maestría en Sociología Jurídica. FCJ y S. UNLP.

esos recursos (sean naturales y/o culturales) y políticas que fomenten la identidad (local, nacional y regional), para lo cual es indispensable el adecuado soporte normativo y funda nuestra insistencia en ese aspecto.

\section{2. Grupo de derechos.}

Al mencionar el derecho al ambiente o el DPC, aludimos a derechos cuyo titular es la sociedad, por eso son también llamados derechos colectivos. Como referencia amplia son los que la reforma reconoció en el capítulo "nuevos derechos y garantías" y en cuyo grupo encontramos entre otros- los derechos de las asociaciones (ONGs) que ejerzan representación de vecinos, usuarios, consumidores; el derecho a la participación de la ciudadanía, el derecho al ambiente, la utilización racional de recursos, el Derecho al patrimonio (natural y cultural) y fueron garantizados por el artículo 43 que consagra la acción de amparo.

Debe también señalarse primero, el "amalgamamiento" existente entre PC e identidad cultural, pues preservar el patrimonio es garantía de identidad. que manifiesta en sus bienes; en segundo lugar que PC vincula el derecho internacional con el derecho interno, lo que exhibe en la complejidad aludida; y finalmente, que en ámbito interno presenta aspectos donde relacionan el derecho civil, constitucional, administrativo, etc., reconociendo diversidad de fuentes desde los derechos culturales (PIDESC) y aun desde el derecho ambiental, aunque asimismo cabe analizarse en perspectiva de derecho humano fundamental, lo que permite hablar del "Derecho humano al patrimonio cultural".

La norma nacional, recepta una materia que puede ser así, ubicada en los llamados "Derechos humanos fundamentales" porque habla de un derecho de todos los habitantes, sin perjuicio de que el art. $43^{11}$-al prever la acción de amparo como vía para protegerlo- aluda a los de incidencia colectiva, mostrando la dimensión colectiva que también ha asumido.

Nuestro constituyente nacional (1994) dejó claro que el vocablo ambiente no circunscribe al entorno físico y elementos naturales sino que añade los que el hombre crea calificando de culturales, en donde ubican los bienes del PC haciendo que la cuestión patrimonial (como la ambiental) supere el concepto de derechos subjetivos delineados en la primera generación de derechos (protegían intereses puramente individuales) extendiendo el concepto y mencionándolo como un "Derecho humano fundamental".

\footnotetext{
${ }^{11}$ Conf. art. $43 \mathrm{CN}$ : Acción de amparo que puede interponer toda persona contra acto u omisión de autoridades o de particulares que lesione, restrinja, altere o amenace -con arbitrariedad o ilegalidad- derechos y garantías reconocidos...
} 
Zendri, L. La protección del patrimonio cultural de Argentina. De la legislación patrimonial a la consagración de un nuevo derecho. Derecho y Ciencias Sociales. Abril 2017. № 16 (Temas relativos al desarrollo regional y local) Pgs 40- 55. ISNN 1852-2971. Instituto de Cultura Jurídica y Maestría en Sociología Jurídica. FCJ y S. UNLP.

Es que la tutela del PC no puede abordarse en Argentina sin atender la tutela del ambiente pues esta última, se satisface con la protección de los recursos naturales y la preservación de los culturales; porque el medio ambiente humano ha sido conformado por la cultura, y así se dijo que "El medio ambiente humano comprende todos los aspectos de la actividad del hombre que, modificando el sistema ecológico natural del que forma parte, afecta su vida y a su bienestar"(Strong, 1975); muestra ello, que abarca aspectos biológicos, económicos y culturales, combinados en una trama con dinámica de transformación permanente (De Castro, 1972:15), transformación de la estructura misma de la comunidad que es resultado de esos múltiples factores.

Estamos frente a derechos con rasgos particulares, entre ellos: conllevan - además de la titularidad personal e individual- una dimensión colectiva, se ubican en la encrucijada entre el derecho público y el privado, y asocian a otros derechos (derecho a la calidad de vida, al desarrollo, a la propiedad, a la educación y la cultura, a la información, a la tutela judicial efectiva, etc.) lo que justifica su ubicación y situación.

En síntesis, decir que el Derecho al ambiente (natural y cultural) tiene naturaleza de derecho de incidencia colectiva, equivale a decir que el "Estado" o "autoridad pública" asume frente a ellos una obligación universal (frente a toda la sociedad y frente a los individuos que tienen y comparten ese mismo derecho); eso ocurre con el Derecho al PC y con los bienes y servicios involucrados, o sea con el derecho al uso y disfrute de los bienes culturales. En este sentido, es útil señalar que la Conferencia de Naciones Unidas sobre Medio Ambiente (Estocolmo 1972) en su declaración de principios para mejorar la calidad de vida de los países como un derechos fundamental del hombre, resaltó la importancia del entorno histórico, cultural, económicosocial y político en que se desenvuelve cada nación y en tal sentido, en Argentina, la Ley 11.723, lo define como: "el sistema constituido por factores naturales, culturales y sociales, interrelacionados entre sí, que condicionan la vida del hombre a la vez que constantemente son modificados y condicionados por este”.

El hombre incesantemente va construyendo su medio, así el “ambiente humano” integra en su geografía, símbolos que abarcan multiplicidad de modos de producción, haciendo que él adopte características propias y funcionamientos particulares en razón de pautas sociales, económicas, políticas y culturales de cada pueblo o ciudad. Eso queda claramente exhibido en América Latina toda, donde el medio ambiente adopta características dispares pues igual de diferente es la geografía, los recursos, la historia, los rasgos culturales y la organización socio-económica y política de los países que la integran, mostrando la necesidad de proteger sus identidades. 
Zendri, L. La protección del patrimonio cultural de Argentina. De la legislación patrimonial a la consagración de un nuevo derecho. Derecho y Ciencias Sociales. Abril 2017. № 16 (Temas relativos al desarrollo regional y local) Pgs 40- 55. ISNN 1852-2971. Instituto de Cultura Jurídica y Maestría en Sociología Jurídica. FCJ y S. UNLP.

La razón de ello es que el desarrollo humano importa una idea de evolución de las condiciones de vida (Sabsay, 1999:269), y así ha dicho la doctrina, que es en la parte dogmática del texto constitucional argentino donde surge con vehemencia la concepción de un modelo de desarrollo en el que confluye la variante ambiental, económica, social y cultural, poniendo en relieve la trascendencia que cobra la preservación y tutela para el desarrollo, ya que Argentina incorporó expresamente el derecho de todo ciudadano al ambiente y visto que él no circunscribe al entorno físico sino que suma los bienes culturales, es que el derecho al PC debe analizarse en perspectiva de Derecho Humano.

\subsection{Derecho humano al ambiente, al patrimonio y a la identidad cultural.}

Conforme vimos, en la concepción de "Derecho humano fundamental" ubica "el DPC", pues esta "generación" de DDHH condicionan el obrar, poniendo límites a la autonomía, al Derecho de propiedad, pudiendo decirse que este derecho humano es una especie de "continente" para la realización de los demás DDHH al limitar los derechos individuales imponiéndoles por ejemplo preservar el PC. En esta generación de derechos inscribe el Derecho al ambiente en general y la preservación del PC en particular ${ }^{12}$ ya que es ssabido que la protección al ambiente no se realiza en una forma global, sino a través de los distintos elementos que lo componen, pudiendo colegir que el bien jurídico tutelado se presenta como un conjunto de bienes naturales y culturales.

Por otro lado, cabe tener presente que el PC viene revalorizado a nivel mundial, y refleja en el mundo jurídico, en la búsqueda de tutela efectiva lo que dio origen a la decisión internacional de preservar legados de numerosas culturas, que llevó a que la UNESCO lo defina como "el legado que recibimos del pasado, lo que vivimos en el presente y lo que transmitimos a las generaciones venideras", lanzando campañas preservacionistas internacionales con sustento en los instrumentos internacionales y principalmente en la Convención del $1972^{13}$-norma rectora a la que Argentina adhirió por Ley nacional de 1978-, que plasmo la obligación de los Estados de efectiva tutela al PC en sus territorios y trae en correlato, la mentada necesidad de modificar

\footnotetext{
${ }^{12}$ El Derecho ambiental vincula al Derecho de los recursos naturales (engloba derechos como el de aguas, de tierras, derecho forestal, marítimo, minero, el derecho de la energía, el derecho a la atmósfera y al espacio aéreo) mostrando que no existe coincidencia íntegra entre ambos, pues además de esos puntos de contacto, el ambiental atiende áreas ajenas a las listadas, como son, los recursos culturales que incluyen el PC, artístico, histórico etc.

${ }^{13}$ La Convención de 1972 define los sitios y elementos que pueden ser incluidos en la Lista del Patrimonio Mundial fijando además, el deber de los Estados-Partes en la identificación y protección de sus bienes por lo que cada uno se compromete a conservar los bienes del Patrimonio Mundial localizados en su territorio y a proteger su propio patrimonio nacional, incluible en la "Lista".
} 
Zendri, L. La protección del patrimonio cultural de Argentina. De la legislación patrimonial a la consagración de un nuevo derecho. Derecho y Ciencias Sociales. Abril 2017. № 16 (Temas relativos al desarrollo regional y local) Pgs 40- 55. ISNN 1852-2971. Instituto de Cultura Jurídica y Maestría en Sociología Jurídica. FCJ y S. UNLP.

las misiones y funciones de las instituciones locales encargadas de protección, custodia, fomento y difusión, en donde inscriben las instituciones educativas.

Se pretende tutela efectiva de los bienes que conforman el PC fomentando el libre acceso del ciudadano al uso y disfrute de los bienes patrimoniales, eso hace que en muchas constituciones quede configurado como Derecho humano fundamental, de tercera generación, porque el reconocimiento "a todo" ciudadano al uso y disfrute de los bienes culturales, deviene esencial para el pleno desarrollo de la personalidad individual y colectiva. De ahí que nuestro constituyente haya incluido expresamente este derecho, imponiendo además a las autoridades y a la sociedad toda, la carga de su protección.

En esta inteligencia, el aludido art. 75 de nuestra CN, dijimos ya que en el inc. 19, imputa al Congreso de la Nación, proveer a la investigación y al desarrollo científico y tecnológico, su difusión y aprovechamiento, y además, le atribuye la obligación de "sancionar leyes de organización y de base de la educación que consoliden la unidad nacional respetando las particularidades provinciales y locales...” y agrega que debe: “...dictar leyes que protejan la identidad y pluralidad cultural...".

Como vemos, los principios que instala nuestra $\mathrm{CN}^{14}$ en la materia, si bien a veces traducen en prohibiciones, deben correlacionarse con las competencias y deberes para las autoridades, entre los cuales, está que el Estado es quien debe controlar el respeto de los valores democráticos y los valores colectivos que identifican el estilo de vida de nuestra comunidad. A esto, el texto constitucional suma también la obligación (del Estado federal) de respetar las particularidades provinciales y locales (manifestación del pluralismo regional) y así el art. 75 inc. 19 denomina "responsabilidad indelegable del Estado" la que le incumbe para que las pautas culturales que ella establece, se hagan efectivas. Eso abarca desde la elaboración de leyes hasta la ejecución de medidas necesarias, por tanto las políticas culturales, deben dar la organización y base al sistema con margen a lo que el texto llama "particularidades" locales, reenviando a la protección de la identidad cultural.

Las leyes del Congreso Nacional de Argentina deben limitarse a proporcionar las pautas globales que deben guiar esos derechos-deberes culturales, y nuestras provincias han de adoptar criterios análogos a los del texto federal, de manera, que ello, respalda el deber provincial de acatamiento, en virtud de la subordinación en que se encuentra el derecho local respecto la Constitución Nacional (federal) y las leyes del Congreso. A esto debemos agregar el rol del Estado que -entre otras- tiene la obligación de alentar la cultura (por ejemplo estimular a

\footnotetext{
${ }^{14}$ Son los que ubican el Derecho a la cultura en molde de la norma fundamental y tratados internacionales
} 
Zendri, L. La protección del patrimonio cultural de Argentina. De la legislación patrimonial a la consagración de un nuevo derecho. Derecho y Ciencias Sociales. Abril 2017. № 16 (Temas relativos al desarrollo regional y local) Pgs 40- 55. ISNN 1852-2971. Instituto de Cultura Jurídica y Maestría en Sociología Jurídica. FCJ y S. UNLP.

quienes trabajan en su área, asignándole un lugar adecuado en el presupuesto de gastos y recursos), con base en el art. 75 inc.19, cuando en su $4^{\circ}$ párr., asigna al Congreso “el deber” de dictar leyes que den protección a la identidad, la libre creación y circulación de las obras de autor y el patrimonio artístico, los espacios culturales y audiovisuales.

\section{El patrimonio y la identidad cultural en la Constitución Nacional.}

Creemos que puede ser de gran utilidad el estudio de diferentes experiencias sobre diversidad cultural, temas que vinculan el campo del PC al de la identidad cultural (IC), porque una sociedad pluralista debe tratar de conciliar la unidad con la diversidad y porque la identidad cultural no se agota en la del individuo aislado con características propias y peculiares sino que habrá de reconocerse la identidad en cuanto integrantes de una comunidad, cada una de las cuales además se expresa en bienes que forman y conforman su patrimonio. Esto conlleva la aspiración de todo hombre a la pertenencia y ubicación en el mundo, y esta identidad, no debe ser entendida como suma de identidades sino que es una calidad dada y mantenida por vínculos religiosos, políticos y fundamentalmente culturales.

Por tanto, reconocer constitucionalmente la IC remite a identidad de personas en un conjunto, que produce constantemente bienes (el PC es dinámico) tangibles e intangibles en los que se expresa y reconoce, lo que da andamiaje a la valorización de tradiciones, localismos y peculiaridades de los distintos grupos que forman el tejido social de una nación.

La identidad receptada expresamente por nuestra reforma es otro de los derechos de incidencia colectiva mencionados, y en tal sentido, el art. 75 impone al Congreso el deber de "reconocer la preexistencia étnica y cultural de los pueblos indígenas argentinos", "garantizar el respeto a su identidad y el derecho a una educación bilingüe e intercultural" (conf. inc. 17), y de manera más amplia aún, el de "dictar leyes que protejan la identidad y pluralidad cultural" (inc. 19); dejando explícito la reforma, que la preservación de la identidad requiere de la defensa contra discriminaciones arbitrarias pero también requiere la tutela de los bienes identitarios en que ella exterioriza, que deben ser conservados para ser trasmitidos a las generaciones venideras.

\section{Estado actual del Derecho al patrimonio cultural.}

La recepción constitucional del Derecho al PC también refiere a las obligaciones del Estado y de la sociedad, lo que vincula a la necesidad y obligación (establecida internacional y localmente) de darle tutela efectiva, $y$ en consecuencia a la necesidad de crear un marco 
Zendri, L. La protección del patrimonio cultural de Argentina. De la legislación patrimonial a la consagración de un nuevo derecho. Derecho y Ciencias Sociales. Abril 2017. № 16 (Temas relativos al desarrollo regional y local) Pgs 40- 55. ISNN 1852-2971. Instituto de Cultura Jurídica y Maestría en Sociología Jurídica. FCJ y S. UNLP.

normativo que permita preservar (a nivel local, nacional y regional) respetando el derecho al uso y disfrute de los bienes que lo conforman, visualizando a la par acciones que habiliten convertirlo en recurso económico para el desarrollo de su ámbito de localización.

Atento ello, el interrogante entonces, pasa siempre a ser: qué preservar, cómo preservar y quien debe preservar en cada ámbito.

Respecto qué preservar, se dijo que la noción "bien cultural" se ha extendido para abarcar no solo la obra arquitectónica monumental y urbanística, la obra de arte en general, etc., mostrando la necesidad de dar tutela a todos y cada uno de los distintos "elementos" contenidos en la definición. Ello, lleva a limitación que trae analizar el tema desde la legislación del patrimonio (distintas y numerosas leyes que versan cada una sobre alguno/algunos de los objetos contenidos en el concepto), mostrando en cambio, la necesidad de enfocar la cuestión desde el Derecho al PC incorporado al ordenamiento jurídico argentino, que permite hablar no sólo de las características del derecho sino también de las obligaciones y facultades que de él emanan.

Respecto a quién debe preservar, es un aspecto intrínseco a la forma en que quedó consagrado, ya que entra en la categoría de cuyo titular es la sociedad toda y la obligación pesa sobre las autoridades y la comunidad toda.

En el caso del PC la importancia de su conservación vincula a preservar la IC o sea a la protección misma de sus orígenes, su cultura, exhibida en los bienes; así, en los debates de la convención constituyente quedó plasmado el sentido que la norma constitucional otorga al "derecho de todos los habitantes" sin perjuicio de darle la acción de amparo (art.43), como vía de protección constitucional.

Esto muestra la dimensión colectiva y los rasgos esenciales que comparte con otros derechos, pero exhibe claramente la relación con la gobernanza ya que decir que tienen tal naturaleza equivale a decir que el Estado (o la autoridad) asume frente a su preservación una obligación universal, dando paso a la necesidad de modernizar las instituciones encargadas de la tutela, protección, custodia, fomento y difusión.

Respecto cómo preservar, quedó dicho decir que el PC debe verse en perspectiva de derecho humano porque en esa concepción, se condiciona el obrar, poniendo límite a la autonomía individual. En el caso bajo análisis y aún dentro del subtipo construido o edificado, el mismo derecho de propiedad queda modificado, pudiendo decirse entonces que el DPC (igual que el Derecho al ambiente) es un "continente" para la realización de los demás derechos 
Zendri, L. La protección del patrimonio cultural de Argentina. De la legislación patrimonial a la consagración de un nuevo derecho. Derecho y Ciencias Sociales. Abril 2017. № 16 (Temas relativos al desarrollo regional y local) Pgs 40- 55. ISNN 1852-2971. Instituto de Cultura Jurídica y Maestría en Sociología Jurídica. FCJ y S. UNLP.

humanos al limitar el de cada individuo imponiéndole obligaciones que hacen a la responsabilidad intergeneracional comprometida en su preservación y hace posible, por ende, que las herramientas de tutela del ambiente puedan ser usadas para la defensa del PC.

En la preservación del PC se debe conciliar pasado y futuro siendo indispensable la afirmación de las identidades (individuales, locales), razón por la que nuestra Constitución, así lo estableció, mediante la obligación de preservar los bienes en que la identidad cultural traduce y manifiesta.

\section{Reflexión final.}

En síntesis, la reforma incorporó el DPC y con ello, su defensa (tutela práctica) puede operar mediante acciones de prevención, de restablecimiento e incluso de indemnización. La reacción contra amenaza de daño puede fundar tanto medidas preventivas (acción de amparo) como también de restablecimiento o reposición al estado de cosas o situación anterior (art. $10831^{\circ}$ párr. del Código Civil), lo que permite rectificar actitudes que vulneren la obligación y el derecho de todos, o las que impidan el acceso, uso y disfrute de ese patrimonio de la colectividad.

También existen en nuestro derecho, posibilidades indemnizatorias mediante el resarcimiento de daños y parte de la doctrina ve igualmente viable el resarcimiento de daños morales no sólo individuales sino también colectivos (Zavala de González, 1997:53 y 1987:283) en marco de lesiones al patrimonio común, aunque quedan respuestas pendientes, por ej., lo atinente a la legitimación. La actuación del grupo por sus órganos no es discutible, pero la ejercitada por la totalidad de sus miembros, es siempre difícil en la práctica. Así, dejo expresado Gozaini al decir: "Las pretensiones en el proceso colectivo dependen de los derechos o intereses que se reclaman. A veces la petición es genérica y de ser declarada admisible, beneficia a la población en general...en otras no identifica favorecidos comunes, como al reclamarse la protección de bienes declarados de pertenencia del patrimonio cultural..."(Gozaini, 2011).

Esto recala en la necesidad de legislación precisa pues para muchos autores, el "afectado" es quien sufre la lesión en un interés personal o diferenciado (Gozaini,1994) y otros, que los afectados "difusamente" son real y efectivamente afectados de titularidad difusa pero el interés de cada componente del colectivo es real, concreto y personal lo que equivale a que los intereses colectivos tornen -a veces- de goce "diluido" $\sin$ que ello signifique pensarlos abstractos o inasibles (Rodríguez Juárez,1993) sino que por el contrario, la multiplicidad de 
Zendri, L. La protección del patrimonio cultural de Argentina. De la legislación patrimonial a la consagración de un nuevo derecho. Derecho y Ciencias Sociales. Abril 2017. № 16 (Temas relativos al desarrollo regional y local) Pgs 40- 55. ISNN 1852-2971. Instituto de Cultura Jurídica y Maestría en Sociología Jurídica. FCJ y S. UNLP.

"afectatios" (algunos directos y otros indirectos o reflejos) agrava la lesión, cosa que ciertamente debería ser resulta mediante una legislación clara y precisa.

Creemos necesaria una ley general sobre PC y puede ser oportuno atender el derecho comparado. El ejemplo de tutela y gestión de otros países puede ser útil para la elaboración de normas que completen y complementen el mandato constitucional argentino, dando efectiva protección a este nuevo derechos y a esta nueva realidad.

Propiciamos analizar el modelo de otros países, entre ellos, la organización, misiones y funciones de instituciones y especialmente la legislación, en la cual es de citar las "normas generales para gestión, protección y salvaguardia del Patrimonio Cultural de Colombia”, los "Manuales para la implementación del proceso de identificación y recomendaciones de salvaguarda"; los "Manuales de Inventario de Bienes de Interés Cultural"; el modelo la Ley General de amparo al Patrimonio Cultural de la Nación del Perú (L 24.047) y Normas complementarias y, por supuesto, atender el mensaje que emana de las piezas culturales que localizadas en dichos países, fueron listadas como Patrimonio de la Humanidad, según la UNESCO.

La problemática del PC es compleja, por eso insistimos en la necesidad de ser encarada desde distintos enfoques por científicos, especialistas, políticos y académicos; y el Derecho comparado nos puede asistir, especialmente a la hora de redactar normas que habiliten la tutela efectiva de este nuevo derecho, el derecho al Patrimonio Cultural.

\section{Bibliografía.}

De Castro,J. (1972) El subdesarrollo, primera causa de contaminación, Ed. El Correo de la Unesco, París.

Gozaini O.A. (2011) Tratado de Derecho procesal constitucional T. 1. Ed. Porrúa, México.

Gozaini o.A. (1994)Legitimación para actuar en materia de amparo, La Ley, 1994-C-967.

Orozco Pardo G. \& Perez Alonso E.(1996) La tutela civil y penal del patrimonio histórico cultural o artístico, McGraw Hill, Madrid.

Rodriguez Juarez M.(1993) La legitimación activa en los llamados intereses difusos. Semanario Jurídico, No 991, 30/06/93.

Sabsay , D (1999) El Valor Desarrollo Humano . En Los valores en la Constitución Argentina, Ed. Ediar S.A. Buenos Aires.

Strong, M (1975)Documentos del Director Gral. del Programa de Naciones Unidas para el Medio Ambiente, Nairobi. 
Zendri, L. La protección del patrimonio cultural de Argentina. De la legislación patrimonial a la consagración de un nuevo derecho. Derecho y Ciencias Sociales. Abril 2017. № 16 (Temas relativos al desarrollo regional y local) Pgs $40-55$. ISNN 1852-2971. Instituto de Cultura Jurídica y Maestría en Sociología Jurídica. FCJ y S. UNLP.

Zannoni E., La reforma constitucional y la protección de intereses difusos. Rev. de Derecho privado y comunitario, N.7 .

Zavala de Gonzalez (1997) Los daños morales colectivos, Foro de Córdoba 1997, № 37.

Zavala de Gonzalez (1997) Los daños morales colectivos y su resarcimiento..., LLBA. 